\title{
Foreigner identification number in Turkey: challenges, threats, opportunities and its role in organizational sustainability development
}

\author{
Mehdi Safaei $^{1^{*}}$, Sajedah Norozpour ${ }^{2}$ \\ ${ }^{1}$ Faculty of Engineering and Architecture (FEA), Department of Industrial Engineering, Istanbul Gelisim University, Istanbul, \\ Turkey \\ ${ }^{2}$ Faculty of Engineering and Architecture (FEA), Department of Civil Engineering, Istanbul Gelisim University, Istanbul, Turkey
}

\begin{abstract}
Employee performance within the organization reflects their knowledge, skills, and values. To this end, identifying the factors, affecting the performance of employees is one of the goals of human-resource improvement in management. The effective role of motivating and reinforcing the sense of worth in an organization's personnel, in improving their efficiency, effectiveness, and productivity as well as enhancing their mental health, are factors that cannot be ignored easily. This is particularly evident in organizations where the workforce is more involved in research activities. One of the key factors is a research organization's sense of responsibility for the organizational problems of its valuable personnel. This research examines the performance diagnosing of the organizational process in Turkish universities and then identifies challenges, threats and opportunities. Finally, suggestions have been made to achieve sustainable organizational development. After identifying and examining the influencing factors, the Weisbord model is examined to evaluate the Performance Diagnosis process of issuing a work permit for foreign professors at a Turkish university. As a result of this study, researchers have made suggestions for university administrators to improve organization and staff performance.
\end{abstract}

Keywords:

Productivity; Sustainability; Performance management; Effectiveness and efficiency; diagnosis model.

\section{Introduction}

Today, various definitions of performance have been proposed by different researchers. In 1998, Robin introduced the most comprehensive definition that is accepted by most researchers.In this definition, performance is the efficiency and effectiveness of assigned tasks and some personal data such as incident creation, work delay, absenteeism and slowness of work.In this definition, efficiency means the ratio of returns to resources used.Furthermore, effectiveness is the extent to which the goals have been met.On the other hand, factors such as absenteeism, slowness at work, delay, and incident creativity can be suitable criteria for performance measurement [1].

Performance is divided into three levels: individual, group, and organizational.

- Factors affecting individual performance:

Ability, learning, personality, perception, motivation [1].

- Factors affecting performance at the organizational level:

Organizational structure, organizational environment, policies, organizational practices, and organizational culture [1].

- Factors affecting group performance:

Communication, leadership, power, politics, group behavior, and conflict [1].

Hersey and Goldsmith have selected seven variables related to effective performance management:ability; clarity; help (perceived organizational support); incentive; evaluationvalidity; environmental compatibility and feedback.

The next step is for managers to combine these factors in a way that they can remember and use.One way to make it easy to recall the items on the list is to make them a common word or an acronym with their first letters(e.g. ACHIEVE),[2].

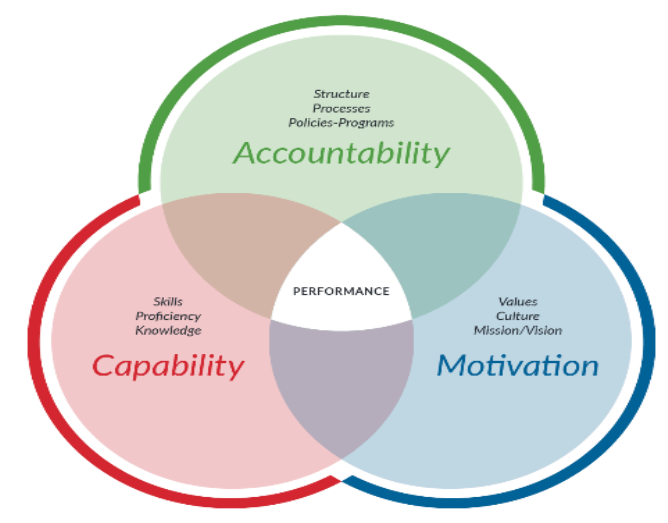

Figure 1. Variables related to effective performance management[2].

Ability: The ACHIEVE model refers to the knowledge, experience, and skills of subordinates performing a specific task [2].Workability or readiness is knowledge and experience[3].Essential components of competence are job knowledge (formal and informal 
apprenticeship that facilitates successful completion of project work) and job-related talent [4].

Clarity (understanding or perceiving a role): Understanding and accepting the place and how the process of that activity (job) is performed.For subordinates to have a complete understanding of the problem, the major goals and objectives, the way to achieve those goals, and the goals and priorities of the goals and objectives (what goals, at what times are most important), should be completely clear to them [5].

Organizational Support: This is the support or assistance that employees need for a successful job. Some factors include sufficient funding (salaries and benefits), equipment and facilities to do the job (software and hardware), support for other organizational units, quality product/service availability. Finally, there is a need for specialized human resources to support the core staff of the organization [6].

Employee Motivation and Desire (Creating Value for Employees): Successfully refers to the motivation to perform subordinate tasks. Moreover,it is regarded to create motivation to complete the particular task being analyzed [7].People are more motivated to complete assignments that have internal or external rewards.If the subordinate has different forms of motivation, the first step is to consider the use of reward and punishment [8].

Evaluation (Feedback): Evaluation refers to daily performance feedback and occasional reviews.The proper feedback process allows the subordinate to constantly be aware of how much work is being done [8].The purpose of this type of feedback is to inform him of his daily performance informally as well as periodic official visits [9].

Employee Credentials: This term refers to the appropriateness and legality of managerial decisions regarding human resources.Employee decisions must be based on performance-oriented policies and evidence [10].

Environmental compatibility:Environmental factors are called external factors that affect performance even with the ability, clarity, support, and motivation on the job.Environmental factors are included competition, government regulations, procurement, etc. [4].Another variable of the study was students' satisfaction with staff performance, namely the satisfaction experienced from satisfying a desire or goal [8].Satisfaction is a function of adapting organizational expectations to individual needs and desires.

\section{Efficiency}

The output rate of employees at a given time is called efficiency. In this definition, efficiency is an indicator of how to use the organization's resources. More output indicates higher efficiency (if resources are not increased). For example, the number of articles and projects a faculty member writes in a given time period, or the number of requests and technical needs of the IT department staff can be met.All of these examples illustrate the movement of these people towards greater efficiency.Proper use of materials, capital, human resources, and time, etc., is a move towards efficiency.Quantitative and tangible indicators or standards must be established to measure performance. Some of these standards and indicators may be as follows[11]:

Number of pages typed per hour to measure typing efficiency, number of quality produced goods in a specified time-frame to measure worker performance or production units, the amount of consumables used in the production of goods; number of students registered for an academic year, the number of certificates issued in a specified time range, etc.

\section{Effectiveness}

A common definition is "effectiveness is the extent to which organizational goals are achieved." The organization can accomplish many goals, such as: improving its position among competitors, employee satisfaction, customer satisfaction, quality of products and services, etc., which measure its effectiveness, with the extent to which the goals are met.Indeed, effectiveness is about paying attention to the returns.

In fact, the concept of quality lies in the effectiveness[12].

Efficiency means using the data (resources) of the organization optimally and appropriately at a lower cost. in other words, with fewer spills.

Effectiveness can be achieved by performing the following:

- Eliminate things that no one should do.

- Allocate the necessary personnel to the organization in order to expedite the execution of tasks

- The remaining work must be done by the manager. 
Even so, by defining effectiveness and efficiency, a brief critique of effectiveness by efficiency has been introduced.The question is, to what extent can we pursue efficiency? Is it always good for an employee who serves more clients? In terms of efficiency, the answer is yes.

However, if the goals of the organization are to have employees with a mentally healthy staff, the quality of customer service, reducing psychological and job stress on staff.

Then, serving more than a specific amount of clients will cause these goals to be compromised, hence, what is the answer?The answer is that performance should continue to improve to the extent that these targets are not harmed.Therefore, the efficiency bar should be stretched to the extent that it does not harm the effectiveness of the organization.

\section{Productivity}

Many specialized dictionaries have defined productivity management as "the ratio of outputs to inputs."Stephen P. Robbins views productivity as a set of efficiency and effectiveness.Therefore, to achieve productivity must act efficiently and effectively.It is effective if the organization can achieve its goals of achieving customer satisfaction.Nevertheless, if the organization achieves the same goal by reducing the number of its employees (customer satisfaction), it will be more efficient than before.As stated in the mentioned example, productivity is a combination of effectiveness and efficiency.

Finally, it can be argued that productivity is an intellectual insight that constantly strives to improve what has been and what is, and with this insight and mentality to do today's things better than yesterday's and tomorrow's better than today's. "Productivity is: doing the right thing in the right way at the right time." Productivity is nothing but doing things right and doing things permanently. In other words, productivity can be written asContinuity in work + effectiveness + efficiency $=$ productivity[13].

\section{Implementing Productivity in an Organization}

Paying attention to the following will help in implementing productivity in an organization[14]:

Productivity is not limited to manufacturing and industrial units. Public (government) and private organizations (such as public and non-profit universities) that generally provide services to the public also need to apply implementation patterns.
Given that productivity is not equivalent to profitability. Profitability can be achieved by selling more expensive products or by providing services at a higher rate.

Increasing production or providing more services along with the rise in the number of Manpower, machinery, etc., does not indicate an effective and efficient use of the organization's resources.

Productivity plans should be comprehensive and include the entire organization and its constituent departments. In addition, increasing productivity should be a continuous plan.

Productivity enhancement plans should be supported by senior managers.And, in these programs, do not forget the participation of employees.

Quantitative indicators for each organizational unit should be included within the plan.Even so, support for implementing productivity enhancement programs should be sought in the organization.

Establish an information system to provide product improvement program enhancements.According to these information systems, the organization's evaluation and rewards system should be aligned with the organization's productivity plans.

Latterly, Productivity measurement should be performed over a period of time, intermittently.

\section{Barriers to Productivity in the Administrative System}

\section{a. Management weakness:}

Weakness in management is one of the main causes of low productivity in administrative organizations.Lack of managers' familiarity with the techniques of planning, organizing, human resource management, reward and punishment, motivational methods, control, inappropriate selection of managers at various levels of their frequent displacement and lack of planning of training courses, leads to poor management and Consequently, it results in a decrease in productivity.

\section{b. Unskilled Human Resources:}

Employees must have the necessary knowledge and skills to perform the tasks assigned to them correctly.Therefore, in order to improve the level of productivity, in addition to considering other characteristics, staffing should be specialized as one of the basic principles in selecting individuals.It should be noted that recruiting and hiring decent staff requires 
the creation of a human resources system in which meritocracy prevails.

\section{c. Lack of proper staff evaluation system:}

Some of the goals of employee evaluation systems are:

- Identifying the weaknesses of staff in doing things and developing training programs to improve it at the organization level

- Employee interest by creating a system of rewards and incentives within the organization

- Establishing a rational criterion for the concession of benefits and reductions in the dissatisfaction and grievances of employees with "biased opinions"

- Therefore, employee evaluation systems should measure their performance and use it as a measure to correct ineffective practices.

- Having a proper evaluation system can be a factor in promoting work motivation.

d. Lack of motivation in employees:

Increasing and improving productivity in the organization is directly related to the motivation of effort in employees.Motivated employees are able to strive to achieve the goals of the organization, reduce costs, and use resources properly.Unfortunately, for many years, downward motivations have emerged as a problem.

\section{e. The dominance of the Spirit of individualism}

If individuals in the organization seek to achieve their particular goals and use the facilities of the organization to obtain their personal goals and intentions, eventually the productivity of the organization achieved in attaining the goals of the organization will be lost.

\section{f. Irresponsible}

Stating a statistical review can be helpful in understanding this area.Useful working hours are announced 6 to 9 hours a week."A study conducted in the year 1986 on the useful working hours of an administrative agency indicates that the official working hours in the organization were 52 hours per week, which means that they had 8 hours of overtime in addition to the 44 hours worked, but useful work" The staff was only 7.8 hours a week. That means even less than the 8 hours of overtime they receive.

\section{g. Various Economic Rent}

"Economic rent is the surplus value that a supplier of a product/service receives under conditions of absolute or relative scarcity to market demand."It applies to any payment that is higher than the fair value of the products or services. This has created many incomes for many individuals and groups that have endured less effort to earn it.The existence of economic rent (which is, of course, available to some people in the community) and discriminatory payments undermine the spirit of effort among the community.In addition, it will eliminate the incentives for creativity, innovation, and entrepreneurship.Subsequently, and because of the difficulty in making a rational connection between effort and performance, it leads to various forms of productivity decline.Economic rent reduces work morale and effort and ultimately reduces productivity in a variety of ways.Excess payments to goods and services (Economic Rent), a spirit of qualification and lack of attention to technical competencies, people's skills, and their ability to get a job have driven people to pursue academic qualifications as a qualification certification.

Scientific Rent is the awarding of posts based on familiarity and relative communication and the disregard of merit criteria in the selection of individuals in specialized matters.

\section{h. High-Pressure Tasks on Managers:}

Many managers in the bureaucracy simultaneously have many responsibilities.Too much work makes them virtually unable to accomplish much of the work at the designated time, properly.This causes the following problems:

- It causes poor manager performance. Man has no infinite capacity. Managers that have different responsibilities, because of overlapping tasks, do most of their work incompletely.

It causes dissatisfaction for clients and employees. The constant absence of the manager due to too many occupations will slow down and stop the client's work and eventually make them unhappy.

- $\quad$ Prevent the emergence of empowered talent with new and innovative ideas and methods.

- Monopoly culture is prevalent in public/private organizations.

- It causes relationships based on mistrust. Duplicate administrative controls, complete with duplicate registrations, too many correspondence receipts, traditional presence and absence systems, etc., which result from distrust-based relationships, have wasted many organizational resources.

i. Process of activities 
The methods of doing work in many "traditional organizations" are unscientific and inexperienced.This has created many problems in the bureaucratic system, including client confusion and employee fatigue in doing things.

\section{Factors affecting productivity}

Factors affecting the productivity of organizations can be divided into two categories: intra-organizational and extra-organizational factors. In the following, these two categories of factors will be discussed.

\section{a. Extra-organizational Factors}

Factors that are outside the organization and affect their productivity are external factors. The most important extra-organizational factors are:

- Cultural factors: Values, habits, and other cultural categories are closely linked to working properly.In a society where achievement, creativity, innovation, avoid wasting of resources, and optimal uses of time are seen as sustainable values, there is an easy way forward for better days than ever before.

- undeniable. Therefore, people with higher productivity are better quality employees, and quality employees are more skilled and professional.

- Organizational Space: Deploying the organization's equipment, tools, and machinery, and the way people are positioned in the organization, can have an impact on how the organization performs.

- Salary: Employees should be paid in a way that is fair to them in relation to the work done.

- Staff Training: Training staff to empower them is nowadays one of the most recognized management strategies in the world. IBM allocated \$ 2 billion in 1985 to its employee training programs, and it is interesting that the net profit of that year was $\$ 6$ billion.

- Technology: Choosing and applying the right technology as tools and methods that can do the job are effective in increasing or decreasing productivity.

- Encouragement and rewards: It is true that salaries are an important factor in the maintenance and performance of employees, but employees want to receive a variety of rewards related to their performance. Rewards can be financial and non-financial.

- Organizational Culture: Having an organizational culture that moves to increase productivity can lead to improved productivity
- $\quad$ Economic Factors:Fluctuations and economic changes in a country can affect productivity. For example: In inflationary conditions, people will have to work more because of the depreciation of the currency. The multi-occupancy phenomenon will reduce productivity.

- Social Factors:Collaboration-based social relationships, social discipline, community-level education, population composition, population growth rates, literacy and health, and unemployment rates are all effective in productivity.

\section{b. Intra-organizational factors}

The factors that are inside the organization's buildings and affect their productivity. The most important intra-organizational factors are as follows:

- Human Resources: The relationship between organizational productivity and human resources is

for the organization and a higher standard of living in the community.

- Quality of Work-Life: One of the fundamental principles in this area is to pay attention to the psychological needs of the employees. Creating a work environment free from nervous stress, building relationships based on intimacy, allowing employees to express their opinions and participate in decisions such as these. In general, an organization that pursues quality work-life programs will see an increase and improvement in productivity within themselves.

- Management style:Research shows that if managers want productivity growth in the short term, the "Mechanistic" approach is responsive, but if they want continuous and sustained growth in productivity growth, they should use the "organic" approach in the organization.

\section{Organizational Diagnosis methods}

Organizational Diagnosis is the process of using behavioral science models and methods to evaluate the current state of the organization and find a way to solve problems or increase productivity.In an Organizational Diagnosis, adherence to an indispensable model is essential for the data needed to 
understand the organization comprehensively and to cover all aspects of the organization.

The model shows where to look for organizational problems and what to look for.The model helps gather all the dimensions of the organization by gathering needed data and categorizing the data collected.
The following table summarizes some of the most commonly used Organizational Diagnosis models in the literature. Table 1 , shows a summary of the most applied methods to organizational diagnosis methods.

Table 1. Summary of most applied for organizational diagnosis methods

\begin{tabular}{|c|c|c|c|c|}
\hline $\bar{\nu}$ & Variables & The dependent variables & The & The main assumption \\
\hline 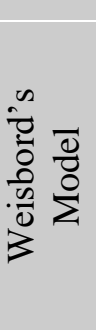 & $\begin{array}{ll}- & \text { Intentions } \\
- & \text { Structure } \\
\text { - } & \text { Communication } \\
\text { - } & \text { Leadership } \\
\text { - } & \text { Rewards } \\
\end{array}$ & $\begin{array}{l}\text { The relationships } \\
\text { between boxes or } \\
\text { variables are not clear. }\end{array}$ & $\begin{array}{l}\text { It is effective because of } \\
\text { the inputs and outputs of } \\
\text { the organization. }\end{array}$ & $\begin{array}{l}\text { The large gap between } \\
\text { formal and informal } \\
\text { systems within each } \\
\text { model is the low } \\
\text { effectiveness or lack } \\
\text { of effectiveness of the } \\
\text { organization. }\end{array}$ \\
\hline $\begin{array}{l}\bar{\theta} \\
\sum_{0}^{0} \\
0 \\
0\end{array}$ & $\begin{array}{ll}\text { - } & \text { Specialty areas } \\
\text { - } & \text { Perspectives } \\
& \text { Implications }\end{array}$ & $\begin{array}{l}\text { The relationships } \\
\text { between variables are } \\
\text { not defined. }\end{array}$ & $\begin{array}{l}\text { The status of } \\
\text { competitors and the } \\
\text { external environment } \\
\text { are taken into account. }\end{array}$ & $\begin{array}{l}\text { Desire for excellence } \\
\text { depends on knowing } \\
\text { the current and } \\
\text { desirable situation. }\end{array}$ \\
\hline 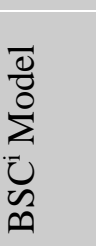 & $\begin{array}{ll} & \text { Financial } \\
\text { Dimensions } \\
-\quad & \text { Customer } \\
\bullet & \text { Internal processes } \\
\text { - } & \text { Innovation }\end{array}$ & $\begin{array}{l}\text { There is a causal } \\
\text { relationship between the } \\
\text { four dimensions of the } \\
\text { model. }\end{array}$ & $\begin{array}{l}\text { The environment is } \\
\text { engendered through } \\
\text { customers } \\
\text { innovation. }\end{array}$ & $\begin{array}{l}\text { No single criterion can } \\
\text { be a clear reflection of } \\
\text { the performance of an } \\
\text { organization. }\end{array}$ \\
\hline
\end{tabular}




\section{Weisbord's 6 Box Model}

This model shows organizational transformation experts what places to look for and what to look for in an organization. As shown in the figure below, the Weisbord identifies six crucial areas or goals (purpose, structure, rewards, helpful mechanisms, relationships, and leadership).These factors must be dealt with properly if the organization is to succeed.Organizational transformation practitioners simultaneously use the processes and activities within each department as a cognitive map to search for problematic symptoms.

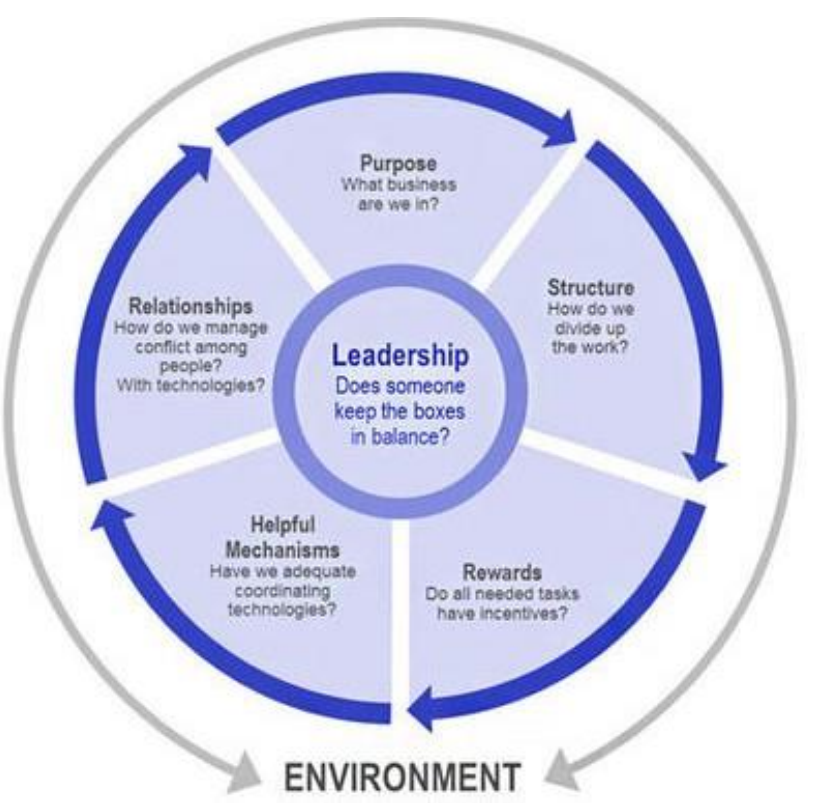

Figure 2.The six box organizational model [15]

According to the Weisbord model (Figure 2), the consultant should focus on the formal and informal aspects of each model segment.The formal system indicates the formal ways of doing; the informal system refers to the actual ways and how things are done. The formal and informal differenceis, what is proposed to happen versus what is actually happening? Weisbord recommends that you gain general insight before selecting change plans by examining these sections or six areas.The Weisbord poses questions for each of these dimensions that should be addressed:

VII. organization members perform assigned tasks to achieve the organization's goals.

Environment dimension: Not seen inside the model, added later and plays an important role in it.

In summary, the Weisbord model will be very useful when the consultant does not have much time to diagnose and when a simple organizational plan is needed or when the client is not familiar with system thinking. In the absence of systematic thinking, this model helps the customer gain an overall picture of
I. Organizational Purposes: The two most important factors in this section are transparency of goals (organization members' awareness of the mission and goals of the organization), and agreement on goals (staff support of the organization's goals).

II. Organizational Structure: The most basic question is whether there is a fit between the structure and purpose of the organization.

III. Relationships: Weisbord has listed three important types of relationships:

$\circ \quad$ Relationships between individuals

- Relationships between organizational units performing different tasks

$\circ \quad$ Relationships between employees with their job characteristics and requirements

According to Weisbord, organizational transformation experts must first identify the interdependence between these factors and then examine the quality of relationships and finally identify conflict management techniques.

IV. Reward's dimension: The consultant's assessment should identify the similarities and differences of formal rewards in the organization (incentive packages, motivation systems) and employee assumptions about reward and punishment systems.

V. Leadership:Weisbord believes the task of the leader is to monitor the interaction between other axes and maintain balance. He outlined four important tasks for leadership.

$\circ \quad$ Setting goals and strategies

- Align all programs with those goals

- Support the convergence of the organization as a whole keeping the organization in line with all conflicts

VI. As a next dimension, Weisbord has mentioned helpful mechanisms or efficient processes. Therefore, applicable mechanisms are the processes that every organization must provide for survival, including planning, control, budgeting, and information systems that help

their organization without having to grasp complex concepts.

\section{Analysis method}

Whereas current research focuses on the development of applied knowledge in a particular context, it can be classified as applied-research. In addition, based on how data is needed to access and analyze it; it can be considered as descriptive-analytical research.The statistical population includes the staff of the 
International Faculty and the related administrative department at a university in Turkey.Given the indefinite statistical population of this study, the sample size was calculated using the Cochran formula with a 95\% confidence level, an estimated error of 0.06 , and $p$ and $q$ were each equal to 0.5.To maximize $\mathrm{n}$, a $\mathrm{P}$ value of 0.5 was taken into account, which, according to the formula, calculated the total number of 53 people.Among the university administrative offices and international faculty members, the sample was selected based on a possible non-probability sample and the domains in the sample. Finally, 53 interviews (and questionnaires) were conducted and analyzed.

Questionnaires and interviews, which are the most important and valid tools in the survey, were used to gather the necessary data. The questionnaire was taken

\section{Results, Findings, and discussion}

Of the demographic characteristics, 39 people (74 percent) are women, and the rests are men.Approximately $22.6 \%$ of them have a master's degree and less, and $77.4 \%$ have a doctorate and a postdoctoral degree.In terms of work experience, with less than 10 years experience with 50.9 percent and with 10 to 20 years with 43.4 percent respectively, the highest frequency.Since the normality (normal distribution) of variables has a significant effect on the type of test, the Kolmogorov-Smirnov test was used.The results of the test are shown in table 2.

\section{Table 2. Statistical Investigation of Normality of Data Distribution in Various Variables Using Kolmogorov-Smirnov Test}

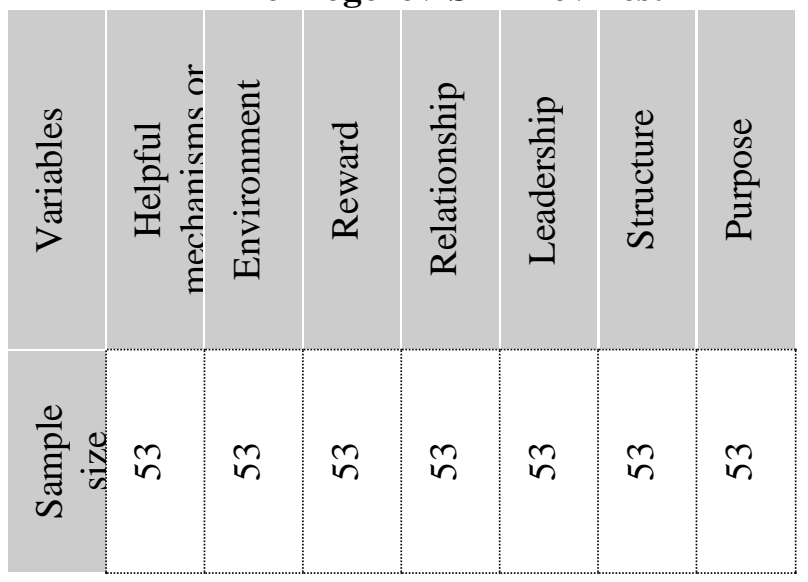

from the standard questionnaire designed by Preziosi and, of course, from the Weisbord questionnaire, which measures the perception of change. The questionnaire is designed as a Likert scale, and the most appropriate method for determining reliability is Cronbach's alpha method. In this study, Cronbach's alpha coefficient was 0.85 and the reliability of this questionnaire was confirmed. To ensure content validity, five experts from the field of management at Sharif University of Technology Management School were used.In addition, the validity of the questionnaire was confirmed by using factor analysis. The Kolmogorov-Smirnov test was used to examine the status of the normal distribution of variables, and the T-test of the samples was used to evaluate the status of the variables in the organization's complication status.Hypotheses were analyzed using SPSS 18 and Lisrel 8.5 software.

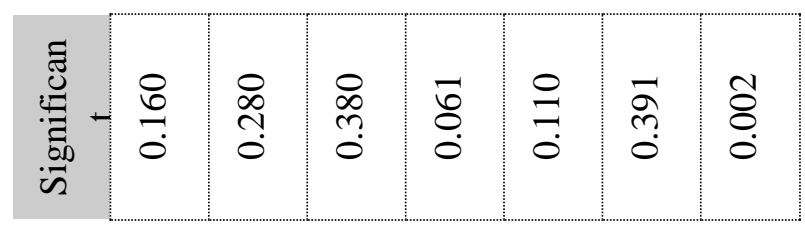

According to the table, the values of significant integers ( $\mathrm{Sig}$ ) of all variables on the target variable are greater than the error value (0.05).In other words, the null-hypothesis for all variables except the target variable is rejected and as a result; all variables have a normal distribution within the target object.

In this study, in order to obtain valid results, the validity of the measurement tool was first analyzed using the Analysis Factor Confirmatory.Afterward, the implementation of the model in the LISREL software indicated that the Weisbord model was well-matched, and the t-statistic was within the significant range (more than 1.96).Therefore, all dimension specifications in the model are verified. As a result, the validity of this model is confirmed.

Given that the scale of the data is considered in the interval plane; therefore, the T-test is not used to determine which one of the seven dimensions of the Weisbord model is in favorable or undesirable levels. The value calculated by the Value-Test is based on a "set of dimension's averages" at a value of 3.95.In addition, the results of the calculated mean test assuming the "sum of the averages obtained" using the single sample test are presented in Table 3.

Table 3.Calculated Averages Based on "Sum of Dimensions Averages" Using "Sample T-Test"

Test Value $=3.95$ 


\begin{tabular}{|c|c|c|c|c|c|c|}
\hline \multirow[b]{2}{*}{$\begin{array}{l}\text { Dimensi } \\
\text { on }\end{array}$} & \multirow[t]{2}{*}{$\begin{array}{c}\text { Tes } \\
\mathrm{t}\end{array}$} & \multirow{2}{*}{$\begin{array}{l}\text { ee of } \\
\text { Freed } \\
\text { om }\end{array}$} & \multirow[t]{2}{*}{ cant } & \multirow[t]{2}{*}{$\mathrm{n}$} & \multicolumn{2}{|c|}{$\begin{array}{c}\text { confidence } \\
\text { interval }\end{array}$} \\
\hline & & & & & $\begin{array}{l}\text { Low } \\
\text { er } \\
\text { limi } \\
t- \\
\mathrm{CI}^{2}\end{array}$ & $\begin{array}{c}\text { Upp } \\
\text { er } \\
\text { limi } \\
\text { t-CI }\end{array}$ \\
\hline Purpose & $\begin{array}{l}1.7 \\
14\end{array}$ & 52 & 0.088 & $\begin{array}{l}0.13 \\
091\end{array}$ & $\begin{array}{c}- \\
0.01 \\
96\end{array}$ & $\begin{array}{c}0.28 \\
15\end{array}$ \\
\hline $\begin{array}{l}\text { Structur } \\
\mathrm{e}\end{array}$ & $\begin{array}{l}- \\
1.2 \\
31\end{array}$ & 52 & 0.220 & $\begin{array}{c}- \\
0.10 \\
727\end{array}$ & $\begin{array}{c}- \\
0.27 \\
90\end{array}$ & $\begin{array}{c}0.06 \\
44\end{array}$ \\
\hline $\begin{array}{l}\text { Leaders } \\
\text { hip }\end{array}$ & $\begin{array}{l}1.1 \\
94\end{array}$ & 52 & 0.234 & $\begin{array}{l}0.11 \\
273\end{array}$ & $\begin{array}{c}- \\
0.07 \\
34\end{array}$ & $\begin{array}{c}0.29 \\
88\end{array}$ \\
\hline $\begin{array}{l}\text { Relation } \\
\text { ship }\end{array}$ & $\begin{array}{l}3.6 \\
21\end{array}$ & 52 & 0.000 & $\begin{array}{l}0.28 \\
727\end{array}$ & $\begin{array}{c}0.13 \\
09\end{array}$ & $\begin{array}{c}0.44 \\
36\end{array}$ \\
\hline Reward & $\begin{array}{c}- \\
5.7 \\
04\end{array}$ & 52 & 0.000 & $\begin{array}{c}- \\
0.51 \\
727\end{array}$ & $\begin{array}{c}- \\
0.69 \\
60\end{array}$ & $\begin{array}{c}- \\
0.33 \\
86\end{array}$ \\
\hline $\begin{array}{l}\text { Helpful } \\
\text { mechani } \\
\text { sms or } \\
\text { efficient } \\
\text { processe } \\
\text { s }\end{array}$ & $\begin{array}{c}- \\
3.9 \\
38\end{array}$ & 52 & 0.349 & $\begin{array}{c}- \\
0.37 \\
273\end{array}$ & $\begin{array}{c}- \\
0.48 \\
01\end{array}$ & $\begin{array}{c}0.37 \\
55\end{array}$ \\
\hline $\begin{array}{l}\text { Environ } \\
\text { ment }\end{array}$ & $\begin{array}{l}0.4 \\
62\end{array}$ & 52 & 0.645 & $\begin{array}{l}0.03 \\
864\end{array}$ & $\begin{array}{c}- \\
0.12 \\
62\end{array}$ & $\begin{array}{c}0.20 \\
35\end{array}$ \\
\hline
\end{tabular}

Determining the desirability of the variables indicated that the value of the T-value of all variables was lower than the absolute value of 1.96 (95\% of confidence), except for the helpful mechanisms or efficient processes, relationship, and reward variables.The findings indicated that there was a significant difference between the mean of the variable of helpful mechanisms or efficient processes, relationship, structure and reward of the hypothetical mean.As shown in Table 2, with respect to their value-T sign, the helpful mechanisms or efficient processesat the Tlevel $(\mathrm{T}=3.94)$, relationshipat the $\mathrm{T}$-level $(\mathrm{T}=3.62)$, and the reward status at the $\mathrm{T}$-level $(\mathrm{T}=5.70)$.As shown in Table 2, with respect to their value-T sign, the relationship status at the $\mathrm{T}$-level $(\mathrm{T}=3.62)$ and the reward status at the $\mathrm{T}$-level $(\mathrm{T}=5.70)$.

\section{Discussion}

The present study aimed to determine the university diagnosis using Weisbord's model. The results of this study showed that the value- $T$ value of all variables except for the helpful mechanisms or efficient processes, relationship, and reward variables was lower than the absolute value of 1.96. Therefore, it can be concluded that the status, purpose, structure, leadership, and environment are at the intermediate level. Nevertheless, there is a significant difference between the relationship variable and the reward with the hypothetical mean. Given the value-T sign, it can be concluded that the relationship status is in the desirable level $(\mathrm{T}=3.62)$, but the reward status is in the undesirable level $(\mathrm{T}=5.70)$.

The results of this study show that fair pay management and payroll are a key area in organizations that contribute to organizational effectiveness.Failure in this area reduces staff excitement and causes the organization to lose specialist staff.Whereas all employees must feel, in contrast to other colleagues and individuals who are similarly employed in other organizations, compensated by the fairness of their services.In this study, organizational failure cases related to serving international employees related to the process of issuing their identification number and work permits were primarily related to the reward system and payroll staff salaries of the related departments. The second problem is the lack of proper mechanisms and structure of the process, in order to control the activities andaffiliated follow-ups. Furthermore, the inadequate skills of HRM staff, and their inexperience, coupled with the unfamiliarity to the process, cannot be easily overlooked, which is at the heart of the mechanism variable.

\section{Conclusion}

Given the specific results, the current status of the university is appropriate in terms of organizational relationships, purposes, leadership, and the environment, but not in terms of coordination mechanisms (including processes), and rewarding.The results showed that most of the failures followed by rewarding and coordination mechanisms (along with processes), as well as organizational structure.The other dimensions were less than three dimensions of reward, coordination mechanisms, and organizational structure.Among which the relationship of the organization is less flawed and because of the positive relationships, and there arefew indications of conflict between employees or managers, good-natured, assistive, honest and supportive people, so they can fully understand the goals of the organization. Therefore, it is essential to redesign the university's organizational structure, given the specific status and position of the organization based on its strategies, as well as the issues and challenges ahead.

In the following, the researchers make suggestions for improvement and modification: 
Designing an accurate and logical performance evaluation system in the university,to calculate the capability of measuring current performance and shows its difference with optimal performance with establishing an appropriate reward system.

Redesigning the university's organizational structure, tailored to the university's own goals and strategies. In addition, it can be a facilitator to solve university problems.

It recommends that future university planning be based on organizational relationships that are sufficiently robust and less defective, with modifications to improve those relationships.

Finally, it is recommended that the university then makes the necessary changes and efforts to reduce stress in the areas most affected.Then, periodically supporter by consulting, and introducing capable people in Turkey.

Without these loved ones, the authors never would have been able to finish this research.

\section{References}

[1] S. Robbins, Organizational Behavior: Concepts, Controversies, Applications, Prentice Hall, 1998.

[2] P. Hersey, K. Blanchard and D. Johnso, Management of Organizational Behavior: Leading Human Resources, Pearson Prentice Hall, 2008.

[3] J. Morelock, T. McNamara and J. James, "Workability and Requests for Flexible Work Arrangements Among Older Adults: The Role of a Time and Place Management Intervention," Journal of Applied Gerontology (JAG), vol. 36, no. 11, p. 1370-1392, 2017.

[4] S. Han, D. Yoon, B. Beixi Lie and C. Chae, "Organizational support on knowledge sharing: a moderated mediation model of job characteristics and organizational citizenship behavior," Journal of Knowledge Management, vol. 23, no. 4, pp. 687-704, 2019.

[5] K. Ritter, R. Matthews, M. Ford and A. Henderson, "Understanding role stressors and job satisfaction over time using adaptation theory," Journal of Applied Psychology, vol. 101, no. 12, p. 1655-1669, 2016.

[6] J. Kurtessis, R. Eisenberger and M. Ford, "Perceived Organizational Support: A MetaAnalytic Evaluation of Organizational Support Theory," Journal of Management (JOM), vol. 43, no. 6, p. 1854-1884, 2017.

[7] N. Gertsson, P. Broberg, J. Friberg and J. Sylvander, "Exploring Motivational Drivers of Audit Employees - A Study Focusing on Generation Y.," Journal of Accounting \& examine the strengths and weaknesses of the diagnosis studies to achieve high levels of excellence.

\section{Acknowledgments}

We would like to thank all our dear colleagues who assisted in completing our questionnaire in this research.We would like to extend our gratitude to our good managers and friends at the Department of International Affairs of the University, Anar Aliyev and Nurlan Ahmadov, who paved the way for researchers. And in this way, it is certainly impossible to pass on the spiritual support of my dear friend, Professor Tariq Elhadary. Last but not least, we would like to thank Prof. NAİL ÖZTAŞ, who has always been

our

Finance, vol. 18, no. 2, pp. 89-105, 2018.

[8] B. Alajmi and H. Alasousi, "Understanding and motivating academic library employees: theoretical implications," Library Management, vol. 40, no. 3/4, pp. 203-214, 2019.

[9] L. Jiehui and Z. Meng, "Effort provides its own reward: endeavors reinforce subjective expectation and evaluation of task performance," Experimental Brain Research, vol. 235, no. 4, p. 1107-1118, 2017.

[10] P. Petrou, E. Demerouti and W. Schaufeli, "Crafting the Change: The Role of Employee Job Crafting Behaviors for Successful Organizational Change," Journal of Management (JOM), vol. 44, no. 5, p. 1766-1792, 2018.

[11] J. Simon , B. Schoefer and J. Zweimüller, "Marginal Jobs and Job Surplus: A Test of the Efficiency of Separations," National Bureau of Economic Research, Cambridge, 2019.

[12] L. Leslie, "Diversity Initiative Effectiveness: A Typological Theory of Unintended Consequences," Academy of Management Review, vol. 44, no. 3, p. 538-563, 2019.

[13] L. Dong, X. Tong, X. Li, J. Zhou, S. Wang and B. Liu, "Some developments and new insights of environmental problems and deep mining strategy for cleaner production in mines," Journal of Cleaner Production, vol. 210, no. 10, pp. 15621578, 2019.

[14] Y. Dave and N. Sohani, "Improving productivity through Lean practices in central India-based manufacturing industries," International Journal of Lean Six Sigma, vol. 10, no. 2, pp. 601-621, 2019.

[15] M. Weisbord, "Organizational Diagnosis: Six Places To Look for Trouble with or Without a Theory," Group \& Organization Management (GOM), vol. 1, no. 4, p. 430-447, 1976. 


\section{Appendix 1:}

\section{Survey questionnaires}

\section{ORGANIZATIONAL DIAGNOSIS QUESTIONNAIRE}

\section{Robert C. Preziosi}

Directions: Do not put your name anywhere on this questionnaire. Please answer all thirty-five questions. Be open and honest. For each of the thirty-five statements, mark " $x$ " to indicate your thinking. We ensure that we will maintain the confidentiality of your opinion.

From time to time, organizations consider it important to analyze themselves. It is necessary to find out from the people who work in the organization what they think if the analysis is going to be of value. This questionnaire will help the organization that you work for analyze itself.

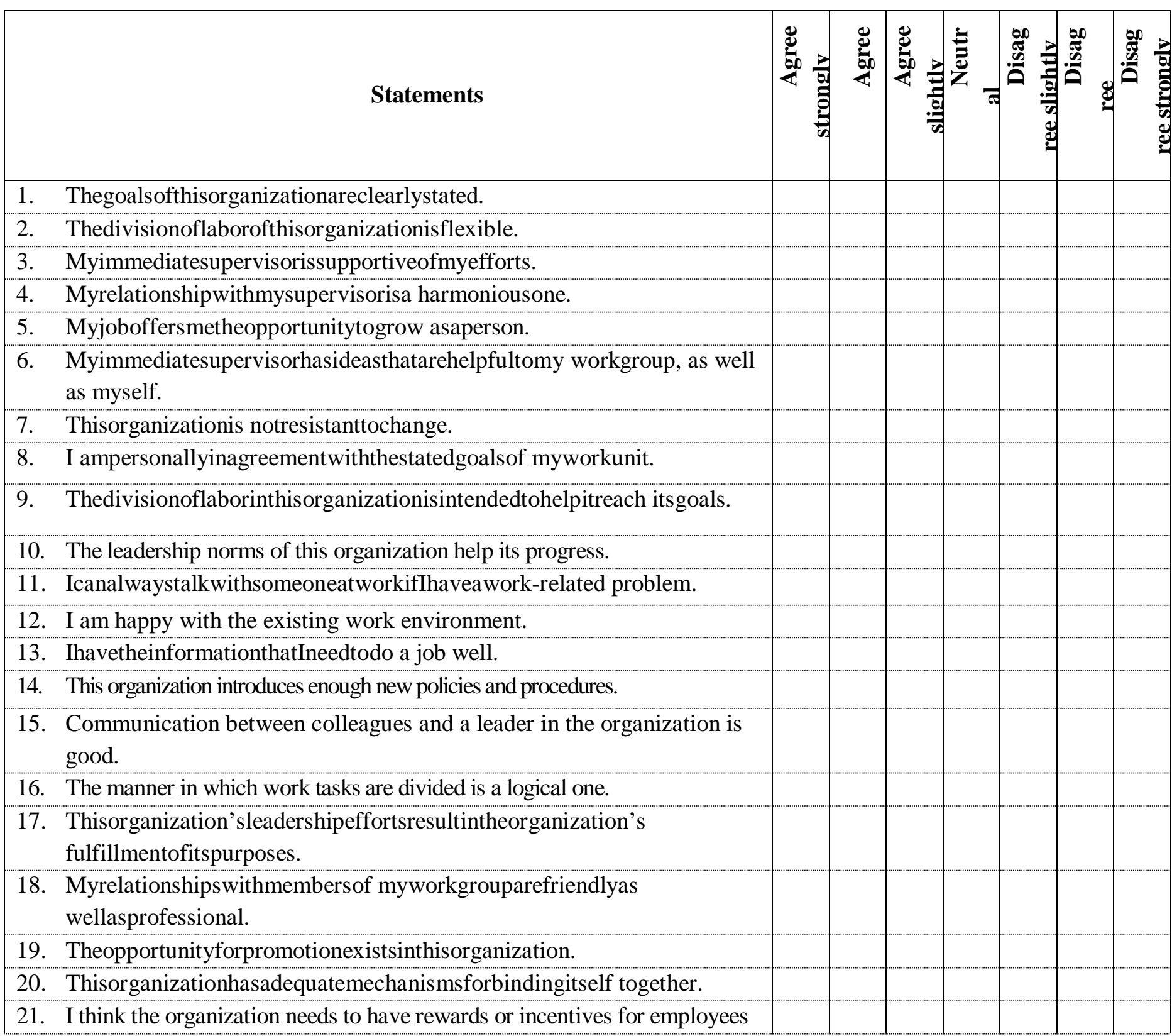




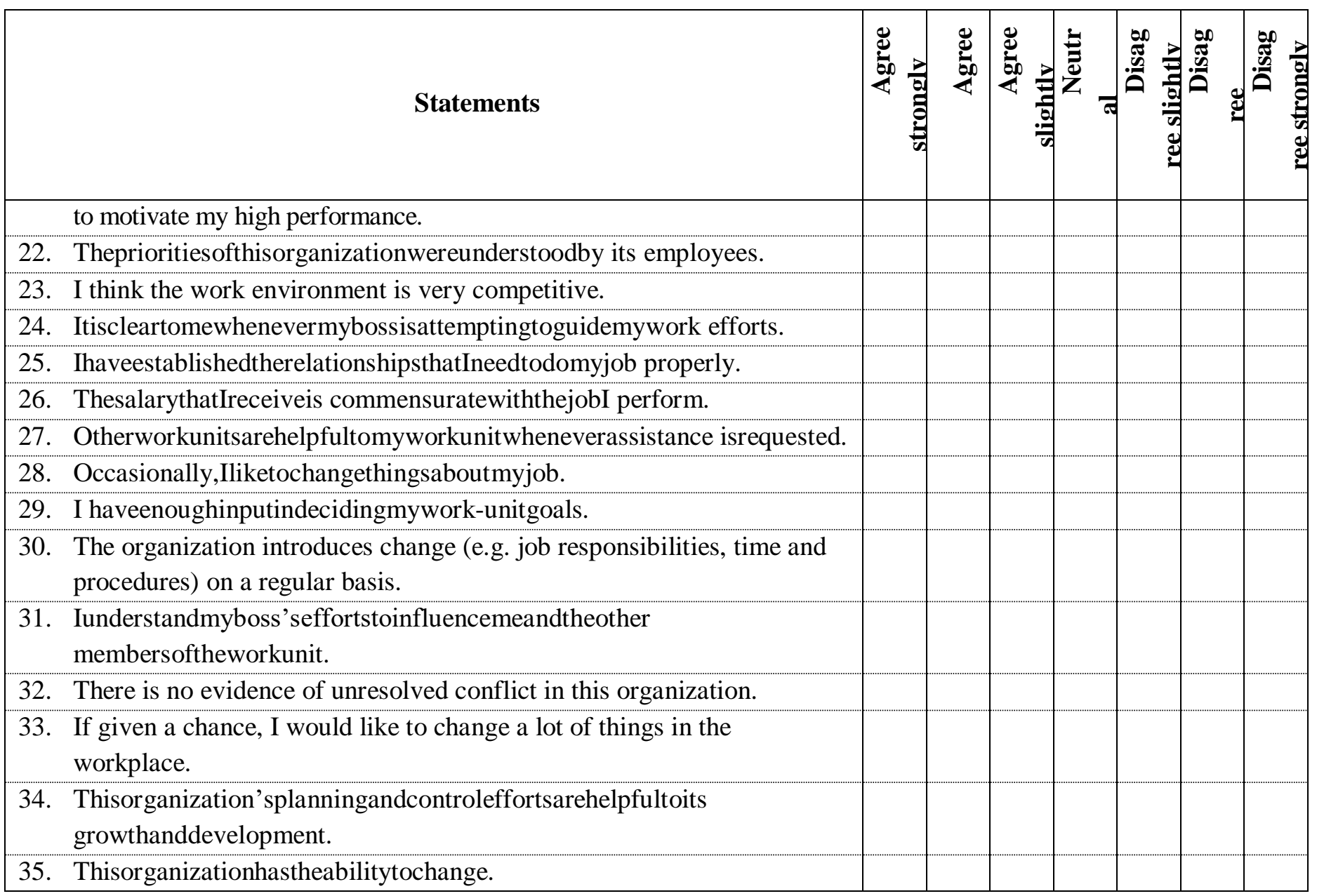

Additional comments you would like to add in response to any of the above questions.

Please describe three things you like the most in the Istanbul Gelisim University and three things you think the IGU can improve in the two columns below.

\begin{tabular}{|l|l|}
\hline \multicolumn{1}{|c|}{ Three things you like the most } & Three things that you would like to change \\
\hline 1. & 1. \\
2. & 2. \\
3 & 3. \\
\hline
\end{tabular}

